\title{
Monetary Policy Shocks and Stock Returns: Evidence from the British Market
}

\author{
A. Gregoriou ${ }^{\text {a }}$, A. Kontonikas ${ }^{\text {b* }}$, R. MacDonald ${ }^{\text {b }}$, A. Montagnoli ${ }^{\text {c }}$ \\ ${ }^{a}$ Norwich Business School, University of East Anglia \\ ${ }^{b}$ Department of Economics, University of Glasgow \\ ${ }^{c}$ Department of Economics, University of Stirling
}

May 2009

\begin{abstract}
This paper examines the impact of anticipated and unanticipated interest rate changes on aggregate and sectoral stock returns in the UK. The monetary policy shock is generated from the change in the three-month sterling LIBOR futures contract. Results from time-series and panel analysis indicate an important structural break in the relationship between stock returns and monetary policy shifts. Particularly, while before the credit crunch the stock market response to both expected and unexpected interest rate changes is negative and significant, the relationship becomes positive during the credit crisis. The latter finding highlights the inability, so far, of monetary policy-makers to reverse, via interest rate cuts, the negative trend observed in stock prices since the onset of the credit crisis.
\end{abstract}

JEL classification: C33; E44; E52; G13.

Keywords: Asset Prices; Monetary Policy; Panel Data.

* Corresponding author: A. Kontonikas, Department of Economics, University of Glasgow, Adam Smith Building, Glasgow, G12 8RT, UK. Email: A.Kontonikas@1bss.gla.ac.uk 


\section{Introduction}

While monetary policy objectives are expressed in terms of macroeconomic variables such as inflation and real output, policy actions affect these variables indirectly and with a lag. On the other hand, financial markets tend to react quickly to the release of new information. Thus, the use of financial data should help to identify a more direct and immediate effect of changes in monetary policy and improve our understanding of the transmission mechanism since asset prices play a key role in several channels. Among asset prices, stock prices are typically closely monitored and are commonly regarded as being highly sensitive to economic news.

As Bernanke and Kuttner (2005) point out, when establishing the link between monetary policy changes and stock returns one should account for the possibility that anticipated policy actions may have already been incorporated by market participants into their investment decisions. Bernanke and Kuttner (2005) use Kuttner's (2001) futures methodology to decompose the federal funds rate changes into expected and unexpected and find that an unanticipated monetary policy tightening exerts a negative impact on the US stock market. Bredin et al. (2007) adopt a similar empirical approach using UK data and find that unanticipated policy changes have a significant impact on both aggregate and the majority of the sixteen sectoral stock returns that they employ.

In this paper we examine the impact of anticipated and unanticipated actions by the Bank of England Monetary Policy Committee (MPC), on UK aggregate and sectoral stock returns. The monetary policy shock is generated from the change in the three-month sterling LIBOR futures contract at the time of the MPC meeting and the sample period runs from June 1999 to November 2009. Unlike Bredin et al. (2007), we utilise both time-series and panel regression analysis. In the context of the latter, we utilize both the cross sectional and time series properties of the data as well as encapsulate possible endogeneity and joint determination by employing a GMM panel estimator, in addition to the standard OLS panel estimator. Moreover, we incorporate a higher level of sectoral disaggregation to estimate the impact of monetary policy announcements on the UK stock market. 
Finally, we are the first study, to the best of our knowledge, to investigate the possibility of a structural break in the relationship between interest rate changes and stock returns around the recent credit crunch. Our results are interesting and novel indicating a significant change in the nature of the stock market response to monetary policy shifts since August 2007.

The rest of the paper is structured as follows. The next section describes the stock market data and the calculation of the monetary policy shock. Section 3 presents the empirical models and results. Section 4 concludes.

\section{Data}

Our sectoral stock returns dataset covers seventy FTSE Industrial sub-sectors which form the ten basic UK industries: oil \& gas, basic materials, industrials, consumer goods, healthcare, consumer services, telecommunications, utilities, financials, and technology. We measure stock returns for subsector $i$ at day $t$ that the Monetary Policy Committee (MPC) meets, $y_{i t}$, as the first difference of the natural $\log$ of the daily closing stock price $\left(S_{i t}\right): y_{i t}=100 *\left(\ln S_{i t}-\ln S_{i, t-1}\right)$. Aggregate stock returns, $y_{t}^{a g g}$, are measured as the first difference of the natural log of the daily closing value of the FTSE 100 index $\left(F T S E_{t}\right): y_{t}^{a g g}=100 *\left(\ln \operatorname{FTSE}_{t}-\ln \operatorname{FTSE}_{t-1}\right)$.

Following Kuttner (2001), we use data from interest rate futures contracts in order to derive the monetary policy shock. In the UK, there is no futures contract tracking the MPC-controlled policy instrument (such as the two-week repo rate used in US-based studies). The closest substitute that exists, and which we use, is a futures contract based upon the three-month LIBOR rate, and this rate is widely accepted as a very good indicator of market expectations of future policy changes. ${ }^{1}$ Thus, the monetary policy shock, $\Delta i^{u}$, is proxied by the change in the rate of the three-month sterling

\footnotetext{
${ }^{1}$ The futures contract is based on the British Bankers' Association London Interbank Offered Rate (BBA LIBOR) for three month sterling deposits at 11:00 on the last trading day. The settlement price is 100 minus the BBA LIBOR rounded to three decimal places. Lindholdt and Wetherilt (2004) employ LIBOR rates at various maturities and find that there has been a clear improvement in the ability of the market to forecast policy rate changes by the Bank of England.
} 
LIBOR futures contract as traded on the Euronext/LIFFE market, relative to the day before the (monthly) MPC meeting:

$\Delta i_{t}^{u}=f_{m, t}-f_{m, t-1}$

where $f_{m, t}$ is the implied futures rate (100 minus the futures contract price) associated with the contract that expires on the month that the MPC meets. ${ }^{2}$ Finally, we measure the expected change in interest rates, $\Delta i^{e}$, as the actual change in the three-month LIBOR rate minus the surprise:

$\Delta i_{t}^{e}=\Delta i_{t}-\Delta i_{t}^{u}$

The sample period under investigation is June 1999 - March 2009, providing us with 119 MPC meetings, which will be the time-series dimension in the panel analysis. ${ }^{3}$

\section{Econometric models and results}

\subsection{Time-series models: Aggregate returns}

We start our empirical investigation by regressing FTSE 100 returns on expected and unexpected interest rate changes:

$y_{t}^{a g g}=\alpha+\beta^{e} \Delta i_{t}^{e}+\beta^{u} \Delta i_{t}^{u}+e_{t}$

where the error term, $e_{t}$, represents factors other than monetary policy that affect the stock market on event days.

[TABLE 1 HERE]

\footnotetext{
${ }^{2}$ For example, to calculate the monetary policy shock associated with the 9/06/2005 MPC meeting, we use the rate implied by the three-month LIBOR futures contract that expires on 13/06/2005. Kuttner (2001) and Bernanke and Kuttner (2005), in their analysis of US monetary announcements adjust the federal funds rate for the number of days remaining in the month. This is necessary in their case because they use the federal funds futures rate, the settlement of which is based upon the average fed funds rate of the last month in the futures life. We do not adjust our LIBOR rates for the number of remaining days in month because in the UK the 3 month LIBOR futures settles at the $3 \mathrm{~m}$-libor of the last trading day.

${ }^{3}$ The particular start date was chosen to take into account two constraints. First, the Monetary Policy Committee meetings commenced on June 1997, and second, prior to June 1999 the Libor future contracts did not have delivery date for each month of the year. Bredin et al. (2007) use an earlier start date (1993-2004), which makes the pre-June 1997 analysis hard to interpret given the lack of scheduled monthly meetings.
} 
The OLS results in column 2 of Table 1 indicate that the estimated stock market response to both the expected and surprise component of monetary policy changes is statistically insignificant. Model 3.1 does not appear to be well specified since the residuals suffer from both heteroscedasticity and serial correlation. Visual inspection of the residual series from this model indicates the presence of two very large negative outliers on August 2002 and October-November 2008. These extreme observations are associated with the stock market downturns of 2002 and 2008. Particularly, late in the summer of 2002 the 'dot-com' bubble burst started reaching its final stage, while autumn 2008 was characterized by the collapse of the Lehman Brothers at the peak of the credit crunch. To account for these outliers, we augment Model 3.1 by including two additive dummy variables:

$y_{t}^{a g g}=\alpha+\gamma_{1}$ DLehman $_{t}+\gamma_{2} D 2002_{t}+\beta^{e} \Delta i_{t}^{e}+\beta^{u} \Delta i_{t}^{u}+e_{t}$

where DLehman $t$ is equal to 1 during October-November 2008 and 0 otherwise, and $D 2002_{t}$ is equal to 1 on August 2002 and 0 otherwise.

From Table 1 column 3 we notice that the fit of the model improves considerably with the adjusted $R^{2}$ increasing by $31 \%$, while the residuals are now free of heteroscedasticity and serial correlation. Apart from the two additive dummy variables, which are highly significant, only one of the monetary policy change variables is significant, the expected component, and that at the $10 \%$ level only. The surprise component effect, while exhibiting a negative sign in line with US evidence by Bernanke and Kuttner (2005), is not significantly different from zero. These findings may be the result of structural instability in the stock market response to monetary policy changes. Indeed, from the onset of the credit crisis on August 2007 onwards, equity market participants have witnessed decreasing valuation in tandem with sharp cuts in interest rates. This suggests a positive, as opposed to the typically negative, association between stock market returns and interest rate changes. In order to account for possible structural change during the financial crisis we interact the expected and unexpected components of monetary policy changes with a (multiplicative) dummy variable: 
$y_{t}^{a g g}=\alpha+\gamma_{1}$ DLehman $_{t}+\gamma_{2}$ D2002 $_{t}+\left(\beta^{e}+\delta_{1}\right.$ DCrisis $\left._{t}\right) \Delta i_{t}^{e}+\left(\beta^{u}+\delta_{2}\right.$ DCrisis $\left._{t}\right) \Delta i_{t}^{u}+e_{t}$

where DCrisis $_{t}$ is equal to 1 from August 2007 onwards and 0 otherwise.

The results in Table 1 column 4 are interesting and novel. The adjusted $R^{2}$ increases to $43 \%$ and, excluding the constant, all variables are statistically significant at the $5 \%$ level or less. The stock market response to both expected and unexpected interest rate changes is negative. Hence, our results are similar to Bernanke and Kuttner (2005) regarding the latter, but differ from them regarding the former. The pre-credit crunch results imply a $-3.26 \%$ one-day return in response to a 50 basis points surprise rate increase. ${ }^{4}$ However, during the credit crunch the estimated coefficient of both surprise and expected changes is positive. This suggests that monetary policy makers have not been able so far to boost stock markets by interest rate cuts highlighting the severity of the current financial turmoil.

\subsection{Time-series models: Sectoral returns}

Our analysis has so far considered the response of a broad stock index to monetary policy. Nevertheless, it is also important to examine the stock market reaction across different sectors in order to examine if any interesting patterns arise. Thus, we estimated Model 3.3 for each of the 70 sectors in our dataset. Overall, the sectoral results are similar to the broad index based results in terms of the signs of the estimated coefficients, indicating a negative (positive) reaction on average to interest rate changes before (during) the credit crunch.

\section{[FIGURE 1 HERE]}

As we see in Figure 1, which plots the histogram of the estimated sectoral coefficients, around $80 \%$ of the expected and surprise-related coefficients are negative before the credit crunch. During the financial crisis, however, more than three quarters of estimated coefficients are positive indicating

\footnotetext{
${ }^{4}$ We repeated the analysis using the FTSE All Share returns and the results (available upon request) were very similar. Moreover, we augmented Model 3.3 by including DCrisis in an additive manner. Results (available upon request) were very similar.
} 
an important change in the nature of the stock market response to policy shifts. Some interesting differences across the sectors include the case of nine industries where their response to (expected and unexpected) policy shifts before the credit crisis is opposite to average behavior. ${ }^{5}$ Also, there are twelve sectors which exhibit negative response to (expected and unexpected) policy shifts during the crisis. ${ }^{6}$ These findings suggest that portfolio diversification opportunities, with respect to monetary policy changes, are not very common but nevertheless do exist.

\subsection{Panel models}

For completeness, we estimate the relationship between monetary policy and stock returns at a sectoral level using panel estimators. We first consider the OLS fixed effects model:

$y_{i t}=\alpha_{i}+\mathbf{X}_{i t}^{\prime} \boldsymbol{\theta}+e_{i t}$

where $y_{i t}$ is defined as above, $\alpha_{i}$ is the time-invariant unobserved sector-specific fixed effect, $\mathbf{X}_{i t}$ is the vector of the explanatory variables and $\boldsymbol{\theta}$ is a vector of coefficients. We examine two alternative cases regarding the explanatory variables vector in Eq. (4). In Model 4.1 it includes the variables of Model 3.3, while in Model 4.2 we add the lagged dividend yield $\left(d y_{i t-12}\right)$ in order to examine the robustness of our results with respect to the presence of an additional control variable related to the financial position of each sub-sector. ${ }^{7}$

One potential drawback with the OLS model is that it does not deal with the likely presence of endogeneity in our data. Although an Instrumental Variable (IV) estimator would address such

\footnotetext{
${ }^{5}$ These sectors are utility companies, environmental services, gambling and casino facilities, industrial machinery and factory equipment, employment services, producers and distributors of pens, paper goods, light bulbs, batteries and cleaning products, insurance brokers, gas distributors to end users and tobacco.

${ }^{6}$ These sectors are environmental services, producers and distributors of pens, paper goods, light bulbs, batteries and cleaning products, manufacturers and distributors of various durable household goods, soft drinks, insurance brokers, property and casualty insurance, tobacco, home improvement retailers, apparel retailers, medical supplies, utility companies and food products.

${ }^{7}$ Bredin et al. (2007) also augment their baseline time-series regression models using, however, not financial position variables but other variables including aggregate stock returns in selected European countries and the exchange rate.
} 
endogeneity it, in turn, fails to capture the cross-sectoral heterogeneity in our data set. Therefore, in order to tackle both the endogeneity and cross-sectoral heterogeneity in the data we use a GMM estimator. Specifically we use the GMM estimator developed by Arellano and Bond (1991) which makes use of internal instruments for each time period to tackle endogeneity.

If $E\left(e_{i t} e_{i z}\right)=0$ holds for $z \neq t$ across all the sectors then it represents the following moment conditions:

$E\left(y_{i, t-z} \Delta e_{i t}\right)=0$ for $z \geq 2 ; \quad t=3, \ldots \ldots ., T$.

If $X_{i t}$ are weakly exogenous then we also have the following additional moment conditions:

$E\left(X_{i, t-z} \Delta e_{i t}\right)=0$ for $z \geq 2 ; \quad t=3, \ldots \ldots ., T$.

The single equation GMM panel estimator generally specifies a dynamic panel model in first differences and exploits the above moment conditions. ${ }^{8}$ Therefore, the lagged (two time periods or more) levels of endogenous and weakly endogenous variables of the model become appropriate instruments for addressing endogeneity. The GMM panel estimator provides consistent coefficient estimates.

\section{[INSERT TABLE 2 HERE]}

The panel estimation results are presented in Table 2. Using OLS, the fixed effects of the panel are significant at the $10 \%$ only when the lagged dividend yield is added (Model 4.2), while with GMM fixed effects are significant across both specifications. The Sargan test results confirm the validity of the instruments in the GMM model. OLS and GMM estimates of Models 4.1 and 4.2 provide similar results which are in line with the broad index findings. Particularly, the stock market response to both expected and unexpected interest rate changes is significantly negative before the

\footnotetext{
${ }^{8}$ The model is transformed into first differences in order to eliminate the fixed effects.
} 
credit crunch and positive throughout it. The additive dummy variables associated with the stock market downturns of 2002 and 2008 are statistically significant. Finally, the lagged dividend yield coefficient is positive and significant which is in conformity with the literature on the predictability on stock returns where higher dividend yield is associated with higher future returns (see e.g. Campbell et al., 1997).

\section{Conclusions}

This paper investigates the impact of anticipated and unanticipated monetary policy announcements of the Bank of England's Monetary Policy Committee (MPC) on UK aggregate and sectoral stock returns. The monetary policy shock is generated from the change in the three-month sterling LIBOR futures contract for a sample period from June 1999 to March 2009. Using time-series and panel regression models we show that both the expected and unexpected components of monetary changes impact significantly on stock returns. Our results document an important structural break in the stock market reaction to monetary policy changes since the onset of the credit crisis. While before the crisis the stock market responds negatively to higher interest rates, the stock returns-interest rate change relationship becomes positive during the credit crunch. The latter finding indicates that, so far, highly expansionary monetary policy has not been able to reverse the negative trend in stock prices highlighting the severity of the ongoing crisis. 


\section{References}

Arellano, M. and S. Bond, 1991. "Some Tests of Specification for Panel Data: Monte Carlo Evidence and an Application to Employment Equations", Review of Economic Studies, 58, 277-297.

Bernanke, B. and K. Kuttner, 2005. "What Explains the Stock Market's Reaction to Federal Reserve Policy?", Journal of Finance, 60, 1221-1257.

Bredin, D., Hyde, S, Nitzsche, D., and G. O'Reilly, 2007. "UK Stock Returns and the Impact of Domestic Monetary Policy Shocks", Journal of Business Finance and Accounting, 34, 872-888.

Campbell, J.Y., Lo, A. and C. MacKinlay, 1997. "The Econometrics of Financial Markets", Princeton University Press.

Kuttner, K., 2001. "Monetary Policy Surprises and Interest Rates: Evidence from the Fed Funds Futures Market", Journal of Monetary Economics, 47, 523-544.

Lildholdt, P. and A. Wetherilt, 2004. "Anticipation of Monetary Policy in UK Financial Markets", Bank of England Working Paper 241. 


\section{TABLES}

Table 1: OLS estimates, FTSE 100 returns.

\begin{tabular}{|c|c|c|c|}
\hline Variable & Model 3.1 & Model 3.2 & Model 3.3 \\
\hline constant & $-0.22(1.9) *$ & $-0.13(1.34)$ & $-0.1(1.00)$ \\
\hline DLehman $_{t}$ & - & $-5.5(6.48) * * *$ & $-5.34(4.94) * * *$ \\
\hline$D 20002_{t}$ & - & $-4.83(4.67) * * *$ & $-4.96(4.93) * * *$ \\
\hline$\Delta i_{t}^{e}$ & $-2.87(1.01)$ & $-4.08(1.75) *$ & $-8.17(3.1) * * *$ \\
\hline $\operatorname{DCrisis}_{t} * \Delta i_{t}^{e}$ & - & - & $14.74(2.98) * * *$ \\
\hline$\Delta i_{t}^{u}$ & $2.97(1.02)$ & $-3.3(1.3)$ & $-6.52(2.27) * *$ \\
\hline $\operatorname{DCrisis}_{t} * \Delta i_{t}^{u}$ & - & - & $12.18(2.22) * *$ \\
\hline \multicolumn{4}{|l|}{ Diagnostics } \\
\hline Adjusted $R^{2}$ & 0.08 & 0.39 & 0.43 \\
\hline$Q(1)$ & $4.837 * *$ & 0.098 & 0.186 \\
\hline$Q^{2}(1)$ & $10.604 * * *$ & 0.314 & 0.219 \\
\hline Het & $4.475 * *$ & 0.507 & 0.303 \\
\hline
\end{tabular}

NOTES: This table reports OLS estimates of Models 3.1-3.3 over the time period June 1999-March 2009 (119 MPC meetings). Figures in parentheses represent the absolute value of the $t$-statistic associated with the null hypothesis that the coefficient is equal to zero. $Q, Q^{2}$ denote the Ljung-Box $Q, Q^{2}$ test statistics for serial correlation and ARCH-type volatility clustering. Het is the Breusch-Pagan-Godfrey $F$ test statistic for heteroscedasticity. ***, **, * indicate statistical significance at the $1,5,10 \%$ level, respectively. 
Table 2: Panel estimates, sectoral stock returns.

\begin{tabular}{|c|c|c|c|c|}
\hline \multirow{2}{*}{ Variable } & \multicolumn{2}{|c|}{ OLS } & \multicolumn{2}{|c|}{ GMM } \\
\hline & Model 4.1 & Model 4.2 & Model 4.1 & Model 4.2 \\
\hline constant & $-0.14(5.91) * * *$ & $-0.39(5.6) * * *$ & $-0.13(4.66) * * *$ & $-0.11(4.03) * * *$ \\
\hline DLehman $_{t}$ & $-3.61(13.35) * * *$ & $-3.5(13.18) * *$ & $-3.79(11.62) * * *$ & $-3.62(11.56) * * *$ \\
\hline$D 20002_{t}$ & $-2.63(10.47) * * *$ & $-2.58(10.48) * * *$ & $-3.13(10.13) * * *$ & $-2.78(9.46) * * *$ \\
\hline$\Delta i_{t}^{e}$ & $-4.66(7.07) * * *$ & $-4.71(7.09) * * *$ & $-4.11(5.56) * * *$ & $-4.01(5.67) * * *$ \\
\hline $\operatorname{DCrisis}_{t} * \Delta i_{t}^{e}$ & $9.81(7.93) * * *$ & $9.6(7.85) * * *$ & $8.12(5.61) * * *$ & $7.65(5.01) * * *$ \\
\hline$\Delta i_{t}^{u}$ & $-4.11(5.73) * * *$ & $-2.39(3.04) * * *$ & $-3.58(4.08) * * *$ & $-3.32(4.16) * * *$ \\
\hline $\operatorname{DCrisis}_{t} * \Delta i_{t}^{u}$ & $8.21(5.98) * * *$ & $6.49(4.68) * * *$ & $5.43(3.32) * * *$ & $5.12(3.05) * * *$ \\
\hline$d y_{i t-12}$ & - & $0.07(3.55) * * *$ & - & $0.06(2.82) * * *$ \\
\hline \multicolumn{5}{|l|}{ Diagnostics } \\
\hline$\alpha_{i}$ & {$[0.43]$} & {$[0.06]$} & {$[0.00]$} & {$[0.00]$} \\
\hline Sargan $\chi^{2}(r)$ & - & - & {$[0.49]$} & {$[0.55]$} \\
\hline
\end{tabular}

NOTES: This table reports panel estimates of Models 4.1 and 4.2 over the time period June 1999-March 2009 (119 MPC meetings) across 70 sectors. Figures in parentheses represent the absolute value of the $t$-statistic associated with the null hypothesis that the coefficient is equal to zero. Sargan tests follow the $X^{2}$ distribution with $r$ degrees of freedom under the null hypothesis of valid instruments. The endogenous explanatory variables in the panel are GMM instrumented setting $z \geq 3 . \alpha_{i}$ are fixed effects. [.] are p values***,**,* indicate statistical significance at the $1,5,10 \%$ level, respectively. 
Figure 1: Histograms of OLS sectoral estimates.

$\Delta i^{e}$

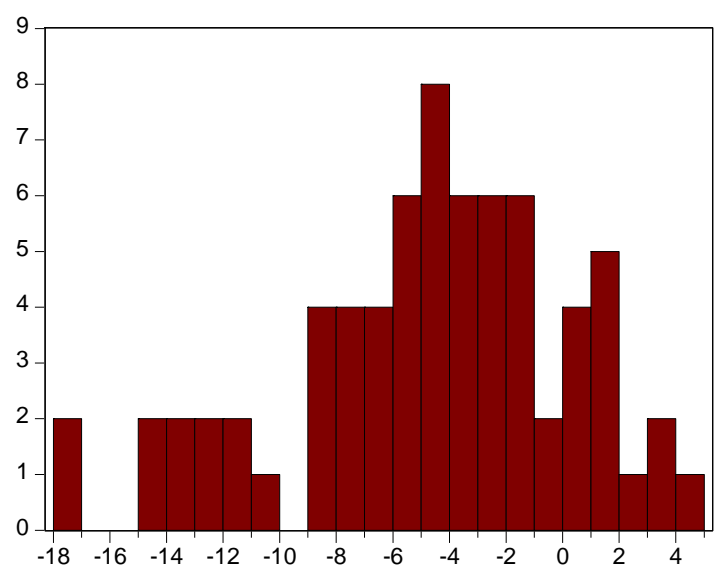

$\Delta i^{u}$

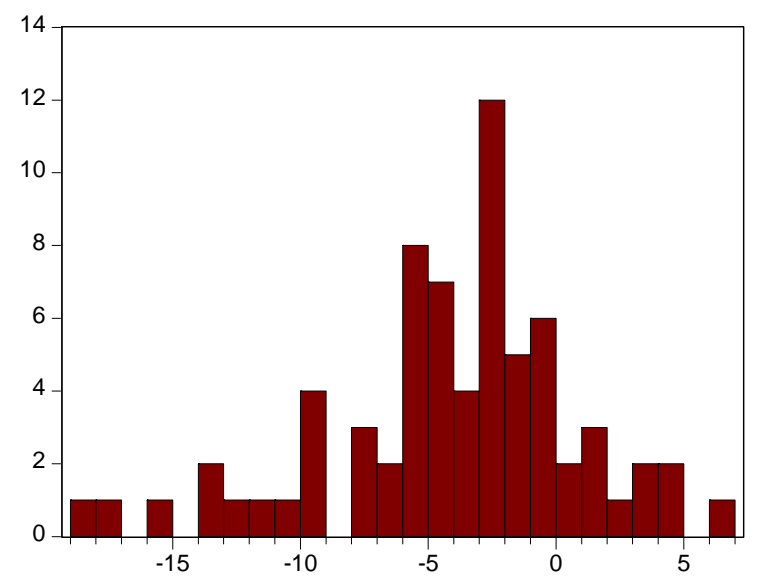

$D C r i s i s * \Delta i^{e}$

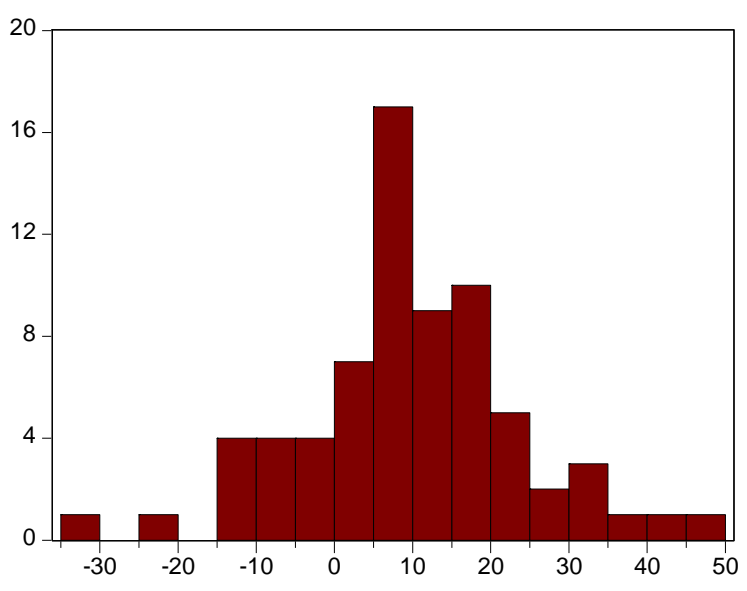

$D C r i s i s * \Delta i^{u}$

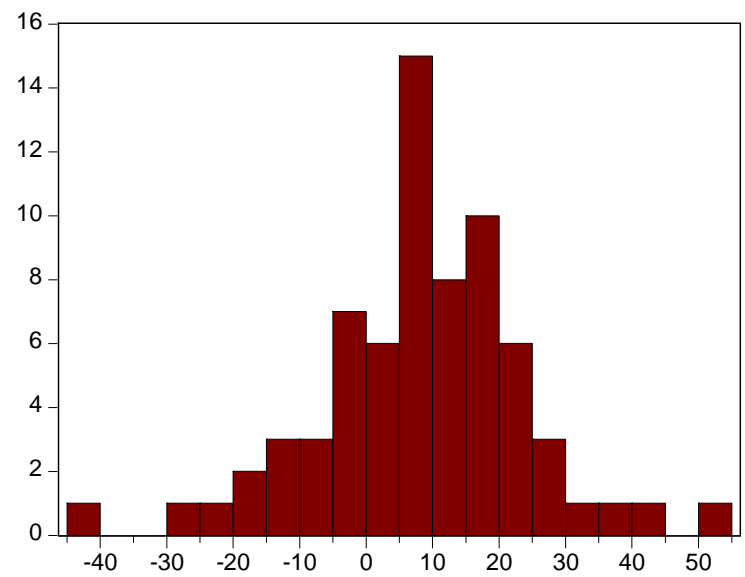

NOTES: These figures show the histograms of the estimated sectoral coefficients from Model 3.3. The header above each figure denotes the variable corresponding to the aforementioned coefficient. 